\title{
JURISPRUDENCIA AMBIENTAL EN ASTURIAS (SEGUNDO SEMESTRE 2018)
}

\author{
Alejandra Boto Álvarez \\ Profesora Titular de Derecho Administrativo \\ Universidad de Oviedo
}


Sumario: 1. Instalaciones deportivas en la servidumbre de protección: Ley de costas vs. Plan de Ordenación del Litoral del Principado de Asturias. 2. Más expectativas de incorporarse a un núcleo rural frustradas por el Plan Territorial Especial del Suelo no urbanizable de Costas (PESC). 3. Sobre la discrecionalidad en el PESC. 4. La relación entre el PESC y el POLA.

Para esta crónica se han elegido una serie de sentencias vinculadas directamente con la protección del litoral, un territorio frágil y singular, donde convergen los intereses de diversos actores, privados, pero también públicos. Algunas de ellas tienen además conexión con precedentes analizados en entregas anteriores de esta sección, y también de la correspondiente a la de novedades legislativas autonómicas.

\section{INSTALACIONES DEPORTIVAS EN LA SERVIDUMBRE DE PROTECCIÓN: LEY DE COSTAS vs. PLAN DE ORDENACIÓN DEL LITORAL DEL PRINCIPADO DE ASTURIAS}

El objeto del recurso contencioso-administrativo 62/2017 es la denegación, por parte del Director General de Ordenación del Territorio y Urbanismo, de una solicitud para la construcción de una cancha de pádel, dentro de la zona de servidumbre de protección del dominio público marítimo-terrestre.

La pretensión de anulación del acto recurrido se fundamenta en el artículo 25.2 de la Ley de Costas, que como es sabido permite la implantación en tales zonas de "instalaciones deportivas descubiertas". Los demandantes centran su argumentación en que toda cancha de pádel tiene en efecto cerramientos laterales, pero que los mismos forman parte del área de juego, por lo que la cancha no debería considerarse como un recinto cerrado. Según su argumentación, las paredes laterales de la cancha no son óbice para que la misma pueda ser considerada "descubierta" ya que debe entenderse que sigue estando "al aire libre". Reproducen en su favor una serie de sentencias de otros TSJ (País Vasco y Región de Murcia) que avalarían su argumentación, por entender que la falta de techo hace que la instalación sea "descubierta" y que las paredes laterales de la cancha no son "cerramientos".

Frente a ello, el letrado del servicio jurídico del Principado mantiene, con base en objeciones técnicas, que la instalación es cubierta, al generar un evidente volumen cerrado por todas sus caras salvo una, lo que produce un recinto cerrado. "Puede no existir cubierta superior -se esgrime-, pero ello no implica 
que no existan las cubiertas laterales: el grado de cobertura es del $80 \%$, esto es, cuatro de las cinco cubiertas posibles, excluyendo del cómputo el terreno o cara inferior".

Al resolver el conflicto, en sentencia 305/2018, de 9 de abril, el TSJA desglosa los presupuestos jurídicos de los fácticos. Respecto a estos últimos, se alinea con los recurrentes y con sus homólogos en otras Comunidades Autónomas, al considerar que la instalación es "cerrada con cristaleras y descubierta", y por tanto sería autorizable por aplicación de la Ley de Costas (Fundamento de Derecho cuarto). Ahora bien, respecto al sustrato jurídico, y en consonancia con las alegaciones formuladas en la contestación a la demanda y que fundamentaban también la resolución recurrida, el Tribunal pasa después a considerar si la instalación se ajusta o no al Plan Territorial Espacial de Ordenación del Litoral Asturiano (POLA), pues sobre la autorización cuestionada confluyen dos normativas complementarias en ejercicio de las competencias que sobre el litoral se atribuyen al Estado y a las Comunidades Autónomas.

Así, y aunque por su naturaleza y conforme a la Ley de Costas la cancha de pádel sería autorizable, no lo es en este caso por expresa previsión del POLA, que no permite la implantación de infraestructuras de ocio o de recreo en esa zona, ya sean de carácter provisional o permanente. $Y$ es que "el uso que se pretende no sólo no está definido como permitido ni autorizable, sino que está expresamente definido como no permitido" (Fundamento de Derecho quinto).

\section{MÁS EXPECTATIVAS DE INCORPORARSE A UN NÚCLEO RURAL FRUSTRADAS POR EL PLAN TERRITORIAL ESPECIAL DEL SUELO NO URBANIZABLE DE COSTAS (PESC)}

En la entrega precedente de esa sección se daba cuenta de las SSTSJA 156/2018 y 157/2018, ambas de 28 de febrero, que resolvían sendos recursos (64/2017 y 61/2017, respectivamente) por la inclusión de determinadas parcelas en el suelo no urbanizable de costas por parte del PESC. En ambos casos los interesados habían solicitado en trámite de alegaciones la exclusión de sus fincas del ámbito de suelo no urbanizable de costas para su incorporación a la delimitación de un núcleo rural, por entender que las fincas 
debían considerarse insertadas en la malla del mismo. Pues bien, un supuesto similar ha sido después objeto de la STSJA 316/2018, de 16 de abril, al resolver el recurso 91/2017. Todo lo que entonces comentamos se reproduce aquí, pero si se ha considerado oportuno mencionar este fallo es porque realiza sobre los anteriores una consideración adicional, vinculada a la supuesta "descoordinación" entre la Administración autonómica y la local invocada por la demanda y la pericia.

En relación con ello el TSJA aborda la cuestión de la potestad autonómica respecto de la potestad urbanística local y, partiendo del principio general de prevalencia de los planes territoriales sobre el planeamiento urbanístico local, recuerda la STS de 12 de febrero de 2016 (recurso 3054/2014) sobre el Plan de Ordenación Litoral de Galicia para apuntar que "la competencia autonómica alcanza todo el territorio para velar por los intereses ambientales y supralocales", de suerte que aunque se afecte y condicione la esfera competencial de las entidades locales, ello no puede reputarse como una vulneración de la autonomía local (Fundamento de Derecho quinto).

Y así se emite el fallo, que desestima íntegramente el recurso e impone condena en costas, con el mismo límite máximo de 1.500 euros que las sentencias antecedentes.

\section{SOBRE LA DISCRECIONALIDAD EN EL PESC}

EI PESC es también el objeto litigioso en el procedimiento derivado del recurso número 72/2017, resuelto por STSJA 474/2018, de 30 de mayo. En los autos los recurrentes censuraban las medidas adoptadas por el PESC en la zona de Niembro para tratar de combatir los problemas de tráfico generados en época estival por la afluencia a las playas vecinas. En concreto, el PESC dispone la ejecución de un aparcamiento y la implantación de medidas de control de tráfico, lo que los recurrentes entienden que en la forma en que se ejecuta perjudica los intereses del pueblo y provoca caos circulatorio, por lo que proceden a presentar demanda argumentando que las medidas del PESC carecen de soporte y justificación. 
Tal pretensión fue combatida por el Principado de Asturias, alegando que precisamente durante la información pública numerosos vecinos de la zona habían solicitado la valoración de aparcamientos disuasorios, y que las medidas de control de tráfico ya habían sido contempladas en planes anteriores.

Al respecto, el TSJA apunta que

el PESC, como todo plan de ordenación territorial, con vocación de estabilidad y armonización de bienes jurídicos, debe incluir necesariamente motivación de sus decisiones, pero nada impide que esa motivación sea idéntica a la acogida por otros instrumentos precedentes de planeamiento. De ahí que el hecho de que el actual Plan mantenga el criterio no supone falta de motivación sino que constituye una motivación legítima. Es más, ha de tenerse presente que la ordenación del territorio sirve a finalidades a largo plazo de tutela de valores y bienes medioambientales y urbanísticos con dimensión global, para una generación o varias y además para toda la ciudadanía, planteamiento o vocación reguladora que postula mantener la línea protectora seguida. Por lo que ningún reproche cabe hacer por el hecho de que un nuevo Plan se alimente de preceptos o reglas incorporadas a planes anteriores, de la misma o distinta naturaleza (Fundamento de Derecho tercero).

En último término, la práctica de las pruebas testificales puso de manifiesto que lo que los vecinos censuraban era la ubicación concreta del punto de control de tráfico, situado en el pueblo cuando el aparcamiento disuasorio lo está a la entrada del mismo, manifestando que "les favorecía más" la ubicación anterior de los aparcamientos en las playas y que "querían que estuviera como siempre". Alegaban también que los coches siguen pasando por el pueblo hasta llegar al punto de control, donde las calles son muy estrechas, carentes de arcenes, con curvas, rampas y descensos.

En relación con ello el TSJA juzga correcto el criterio del PESC por adoptar medidas razonables y razonadas. Y citando una STSJ de Cataluña recuerda que lo determinante para apreciar la corrección de tal decisión no es que 
existan otras igualmente factibles, funcionales $u$ operativas sino demostrar que la adoptada es irracional, arbitraria o incongruente en los términos expuestos, ya que de no ser así la discrecionalidad de la Administración debe prevalecer sobre las opiniones o las conveniencias subjetivas de los afectados, desde cuyo prisma y por los razonamientos expuestos procede desestimar el recurso y condenar al pago de las costas, limitándolas a $1.000 €$ (Fundamento de Derecho cuarto).

\section{LA RELACIÓN ENTRE EL PESC Y EL POLA}

Formalmente, también el PESC es el objeto de recurso en el procedimiento 74/2017, resuelto por STSJA de 23 de abril de 2018. Los recurrentes consideran que el PESC actúa sin rigor, fundamento ni justificación en las previsiones que adopta respecto a los campamentos de turismo en general, y en particular respecto al de su propiedad. Este se categoriza en el PESC como de impacto paisajístico severo acogiendo el criterio que recoge también el POLA, que se pretende asimismo impugnar de manera indirecta.

Frente a ello, la Administración del Principado recuerda que tal impacto paisajístico severo en efecto venía ya previsto en el POLA, lo que exigía su desaparición en el plazo más breve posible. A partir de ahí expone que el PESC sigue en materia de campamentos de turismo la línea del POLA, al identificar entre otros ese campamento como uno con características y emplazamiento incompatible con una mínima sensibilidad ambiental o paisajística. Pero, sobre todo, sostiene que no cabe impugnar de manera indirecta el POLA, en la medida en que falta el presupuesto para ello, que es la existencia de un acto de aplicación.

EI TSJA conviene, efectivamente, en que el PESC no es una aplicación del POLA,

por más que sus previsiones acerca del [campamento en cuestión] se mantengan en el nuevo instrumento de planeamiento, no nos encontramos ante una impugnación indirecta del POLA, sino ante su impugnación directa. En otras palabras, el POLA no es la norma de cobertura que presta sustento y fundamento a lo acordado en el PESC ahora impugnado sino que éste completa y especifica lo 
anticipado en materia de protección costera por aquel, en el ejercicio de la potestad de planificación territorial reservada a la Comunidad Autónoma e inspirada en la sostenibilidad y tutela ambiental y paisajística en relación a los terrenos próximos a la costa.

Y es que

no debe obviarse en primer lugar, que estamos ante dos instrumentos de planificación (POLA y PESC) que participan de naturaleza normativa, de manera que pueden innovar el ordenamiento jurídico bajo nuevos criterios con amplio margen de discrecionalidad y respetando la legislación urbanística, y en segundo lugar, que el PESC es norma planificadora posterior y especial, por lo que su regulación es prevalente y desplaza la existente en el POLA.

Por lo que la impugnación que se pretende del POLA no es indirecta, sino directa y por tanto extemporánea, de forma que no puede acogerse (Fundamento de Derecho segundo).

En relación con la presunta falta de motivación en la decisión del PESC y su falta de justificación o rigor, el TSJA destaca que, precisamente la continuidad con la línea del POLA, puede verse como una motivación legítima garante del principio de confianza legítima. $Y$ que la categorización otorgada al campamento por el PESC lo es en consonancia con los conceptos jurídicos indeterminados que para el suelo de protección de costas contempla el legislador asturiano (áreas de influencia de las playas, vistas al mar y otras que se consideren relevantes). Por ello, el recurrente tendría que haber acreditado la irracionalidad de la discrecionalidad del planificador en la interpretación de esos conceptos para poder concluir la disconformidad a Derecho del PESC. Y ello en este caso no concurre, pues se apunta que

el propio informe aportado por la recurrente destaca que el camping litigioso se asienta en una comarca de elevado valor paisajístico, aunque señala que la fragilidad visual de la zona es de carácter bajo, pero a la postre reconoce que su presencia origina un impacto sobre la calidad del paisaje y aunque se trata de minimizar sus 
efectos paisajísticos, viene a proponer una serie de medidas para su integración paisajística, a medio de la instalación de pantallas vegetales perimetrales, malla de ocultación, recubrimiento del muro exterior mediante aplacado y plantaciones arbustivas en el interior de las instalaciones, que no hace sino corroborar la categorización normativa del [campamento] como de impacto paisajístico severo en el que solo podrán ser autorizadas obras y uso dentro del recinto existente y con carácter precario, atendiendo así a la compatibilidad del efecto del campamento con los valores paisajísticos y ambientales, puesto que no existe prohibición de tales garantías para que la Administración reglamente a través del PESC un trámite - labor de categorización de campamentos bajo esa concreta perspectiva y cara a determinar sus posibilidades desde la situación de fuera de ordenación, sin que por ello se vulnere el derecho de propiedad que queda en todo momento salvaguardado, ni quiebre el principio de igualdad al no darse término válido de comparación (Fundamento de Derecho tercero).

Y por ello se desestima el recurso en su integridad (ya que no cabe una inadmisibilidad parcial) y se imponen las costas con el límite máximo de 1.500 $€$ por todos los conceptos. 